\title{
Driving High Inclination to Complete Massive Open Online Courses (MOOCs): Motivation and Engagement Factors for Learners
}

\author{
Lee Yen Chaw ${ }^{1}$ and Chun Meng Tang ${ }^{2}$ \\ ${ }^{1}$ UCSI University, Malaysia \\ ${ }^{2}$ James Cook University Singapore, Singapore \\ chawly@ucsiuniversity.edu.my \\ chunmeng.tang@jcu.edu.au \\ DOI: 10.34190/JEL.17.2.05
}

\begin{abstract}
Today, online learning is prospering from the widely available and easily accessible connection to the Web. Massive open online course (MOOC) platforms such as Coursera, edX, and Udemy have made available several thousands of short courses at several difficulty levels in a wide variety of disciplines, ranging from business, computer science to literature, for learners to select from. Learners who are looking to earn credentials for career advancement or personal interest would find MOOCs attractive not only because of the time and place flexibility these courses offer, but also because of the free enrollment or the very small certificate fee upon completion, as well as the emergent recognition these courses are receiving for their high quality learning delivery from leading educational institutions. Learners who enroll in a MOOC would typically need to participate in various learning activities and complete a few assessment tasks to complete the course. However, it has been commonly reported that the completion rates of MOOCs are low. Based on the common notion that when learners are more motivated to learn, they are likely to better engage in learning and have a higher likelihood to complete a MOOC, this study adopted the Motivation and Engagement Scale (MES) by Martin $(2007,2009)$ to collect responses from university students to examine whether positive motivation resulted in positive engagement; whether negative motivation resulted in negative engagement; and how positive or negative engagement swayed learners' inclination to complete a MOOC if they were to enroll in one. Findings show that there was a statistically significant positive relationship between positive motivation and positive engagement, between negative motivation and negative engagement, and between positive engagement and inclination to complete a MOOC. However, the relationship between negative engagement and inclination to complete a MOOC was statistically not significant. Findings of this study can be useful to MOOC providers and learners in their effort to develop strategies to increase completion rates of MOOCs.
\end{abstract}

Keywords: inclination to complete, learning engagement, learning motivation, massive open online course, online learning

\section{Introduction}

Massive open online courses (MOOCs) provide learners worldwide access to a wide range of online educational opportunities at zero or low fees (Jung and Lee, 2018; Phan et al., 2016; Zhou, 2016). Today's MOOCs are available in various forms, from weeks-long short courses to months-long specializations or online degrees (Shah, 2018a). The Web-based delivery approach gives learners much flexibility and greater autonomy in their learning process, and this makes MOOCs particularly appealing to learners, who recognise the need for continuous learning for personal or professional development, but are facing time and space limitations.

MOOCs are often affiliated with educational institutions, e.g. Stanford, Harvard University, MIT, Open University, Tsinghua University, and so on (Shah, 2017). Top MOOC providers such as Coursera, edX, Udacity, FutureLearn, and XuetangX offer some 9,000 MOOCs on a wide range of topics, such as technology, business, social sciences, science, and so on (Swigart and Liang, 2016; Shah, 2018b). Shah (2019) reported that, as at the end of 2018, Coursera had 37 million registered users, edX 18 million, XuetangX 14 million, Udacity 10 million, and FutureLearn 8.7 million.

However, the self-paced learning approach poses a self-discipline challenge to MOOC learners. Only a small percentage of MOOC learners successfully completed their courses (Hone and El Said, 2016). Bolliger et al. (2010) opine that the low completion rates may be because of lack of face-to-face or social interaction with other learners, which could lead to a feeling of isolation, and eventually loss of motivation. As low completion rates are a major concern to MOOC providers and learners, there have been calls for an investigation to examine MOOC learners' expectations and motivation to improve completion rates (Chen and Jang, 2010; Watted and Barak, 2018; Shapiro et al., 2017, Zhang, 2016). 
Past studies have examined the factors behind MOOC learners' motivation or engagement levels; e.g. the effect of perceived reputation, perceived openness, perceived usefulness, perceived enjoyment, and user satisfaction on intention to continue (Alraimi et al., 2015); and the effect of academic self-efficacy, teaching presence, and perceived usefulness on learning engagement (Jung and Lee, 2018). However, it still remains unclear what the cognitive and behavioural factors are that affect learners' inclination to complete MOOCs. To fill in this gap, this study adopted the Motivation and Engagement Scale (MES) by Martin (2007, 2009) to examine the positive and negative motivational thoughts and engagement behaviours that could affect learners' inclination to complete a MOOC if they were to enroll in one.

The MES has been commonly adopted for motivation and engagement studies in conventional face-to-face learning environments; e.g. elementary schools (Martin, 2009), high schools (Andrew et al., 2019; Martin and Elliot, 2016), and universities (Yin and Wang, 2016). This study is an attempt to adopt the MES to examine motivation and engagement in an online learning environment. It is also common for past studies to conceptualise motivation or engagement as a unidimensional or bidimensional construct; e.g. perceived reading competence, intrinsic value, and classroom engagement (Whitney and Bergin, 2018); intrinsic motivation, extrinsic motivation, and behavioural engagement (Hornstra et al., 2018); and mastery approach goal orientation, performance approach goal orientation, and academic engagement (Mooney et al. 2016). Adopting the MES provides this study with an opportunity to assess the multidimensional higher-order structure of the motivation and engagement constructs.

The following sections provide an overview of massive open online courses, review learning motivation and engagement and the Motivation and Engagement Scale, introduce the research model, describe the data collection method, present the data analyses and results, and conclude the paper.

\section{Research background}

\subsection{Massive open online courses}

MOOCs present learners with an alternative to traditional education beyond physical limitations (Hone and El Said, 2016), and are quite distinctive in some ways from other learning environments (Alraimi et al., 2015). Learners can review lecture videos, attempt exercises or quizzes, or read course materials at their own pace and complete an entire online course within weeks or months.

MOOCs are "massive" because learner enrollment can be in the hundreds or thousands; are "open" because any learner who is interested in a course can enroll without restrictions and for free; are "online" because courses are delivered virtually on the Web to learners worldwide; and are regarded as courses because they consist of lessons and learning activities that are to be completed within a certain time frame (Major and Blackmon, 2016).

Learners can choose to enroll in a MOOC at no cost, although other fee-paying options from certificates, micro-credentials, university credits, to online degrees are also available (Maxwell et al., 2018; Shah, 2018a). Learners enroll in MOOCs for reasons such as personal flexibility and control (Clayton et al., 2010); learning opportunities with leading universities (Alario-Hoyos et al., 2017); personal benefits (e.g. growth and enrichment, general interest); educational benefits (e.g. experience of undertaking an online course, certification, school relevance); and career benefits (e.g. research relevance, product development, professional competence) (Watted and Barak, 2018).

Despite the advantages of MOOCs, their course completion rates are lower than that of other learning environments (Alraimi et al., 2015). Maxwell et al. (2018) studied four MOOC implementations in healthcare education to conclude that course completion rates varied from $2 \%$ to $13 \%$. This could be because, as the learners enrolled in the courses at zero cost and were not given course credit, their course commitment and engagement levels were low. Hew and Cheng (2014) summarize that the reasons for MOOC incompletion include lack of incentives, difficulty understanding the course material, and other personal or work priorities. Shapiro et al. (2017), having interviewed 36 participants in two MOOCs, reported reasons such as lack of time, previous bad classroom experience with the subject matter, inadequate background, and lack of resources such as money, infrastructure, and Internet access. 


\subsection{Learning motivation and engagement}

Martin (2007, 2009) defines motivation as one's desire for achievement. Driven by personal cognition and emotion, one may exhibit positive or negative motivation towards learning or work. On the other hand, engagement is about the positive or negative behaviours that reflect one's motivation levels. Ben-Eliyahu et al. (2018) and Lee et al. (2016) support that motivation drives engagement behaviours. Oga-Baldwin et al. (2017) point out that the extent of being engaged in active learning is a reflection of one's motivation levels.

Past educational studies have examined learning motivation in two main categories: intrinsic and extrinsic. Intrinsic motivation is related to individual attitude, individual expectation, challenging goals (Law et al., 2010); value beliefs in learning (Oga-Baldwin et al., 2017); desire for knowledge (Hsieh, 2014); and intrinsic satisfaction (Lin et al., 2017). On the other hand, extrinsic motivation is concerned with reward and recognition, punishment, social pressure and competition (Hsieh, 2014; Law et al., 2010; Lin et al., 2017; OgaBaldwin et al., 2017).

Besides intrinsic and extrinsic motivation, Hsieh (2014) expands motivation to include such elements as task value (e.g. task usefulness), ability belief (e.g. positive beliefs in learning), and expectancies for success (e.g. performance expectation). Clayton et al. (2010) describe motivation in terms of achievement goals (e.g. reasons for engaging in a task) and self-efficacy (e.g. perception about one's ability to complete a task). BenEliyahu et al. (2018) suppose that motivation consists of self-efficacy, mastery goal orientations, and performance goal orientations.

Past educational studies have also examined learning engagement in different forms. Lee et al. (2016) explain that engagement is behavioral (e.g. task completion), affective (e.g. feelings toward task), and cognitive (e.g. mental effort). Ben-Eliyahu et al. (2018) and Oga-Baldwin et al. (2017) share similar conceptualisation that engagement is about participation in learning activities, and it consists of the three key components of behavioral engagement, emotional engagement, and cognitive engagement. Hsieh (2014) suggests that three types of learner behaviours exhibit signs of engagement, i.e. cognitive effort, active participation, and interactions with instructors.

Green et al. (2012) suggest that motivation and engagement levels play a key role in academic performance. In a study of undergraduate students, Cazan (2015) highlighted that learning motivation had a positive relationship with engagement. In another study, Chen and Kraklow (2015) also reported a significant relationship between intrinsic motivation and learning engagement. In a study of the interrelationships among learners' problem-solving outcomes, motivation, and engagement in game-based learning, Eseryel et al. (2014) informed that learners' motivation influenced their engagement during gameplay, which in turn affected their problem-solving abilities.

Based on the fundamental links to need achievement and self-worth motivation theory, attribution theory and control, self-efficacy and expectancy-value theory, and motivation and self-determination theory, Martin (2007, 2009) developed the Motivation and Engagement Wheel (Wheel) to depict the positive and negative dimensions of student motivation and engagement. The Wheel consists of four main dimensions, i.e. positive motivation, positive engagement, negative motivation, and negative engagement. In each main dimension, there are several subdimensions. Table 1 presents the main and subdimensions of the Wheel.

Together with the Wheel, there is an associated Motivation and Engagement Scale (MES) (Martin, 2007, 2009, 2016b). The MES has a total of 44 indicators for the 11 subdimensions. Each of the subdimensions of the main dimensions, i.e. positive motivation, positive engagement, negative motivation, and negative engagement, is manifested by four indicators. The MES has been validated in multiple studies with junior school, high school, and university students of different countries such as Australia, China, Jamaica, North American, and the UK (Liem and Martin, 2012; Martin et al., 2017; Martin et al., 2018; Martin et al., 2015; Yin and Wang, 2016). Yin (2018) adopted the MES in a study of undergraduates in China to examine the relationships among student motivation, engagement, and mastery of generic skills as learning outcomes. The findings largely confirmed the relationships among the constructs as hypothesised by the MES. 
Table 1: The main and subdimensions of the Wheel

\begin{tabular}{|l|l|l|}
\hline Main dimensions & Subdimensions & Definitions \\
\hline \multirow{3}{*}{$\begin{array}{l}\text { Positive } \\
\text { motivation }\end{array}$} & Self-belief & Believing and having confidence in one's ability to perform well \\
\cline { 2 - 3 } & Valuing & Valuing learning for its usefulness, importance, and relevance \\
\cline { 2 - 3 } & Learning focus & Learning to solve problems and develop skills \\
\hline \multirow{3}{*}{$\begin{array}{l}\text { Positive } \\
\text { engagement }\end{array}$} & Planning & Planning work and monitoring one's progress in completing the work \\
\cline { 2 - 3 } & Task management & Managing time effectively for study and tasks at hand \\
\cline { 2 - 3 } $\begin{array}{l}\text { Negative } \\
\text { motivation }\end{array}$ & Persistence & Being persistent in solving difficult problems and not giving up \\
\cline { 2 - 3 } & Anxiety & Feeling nervous when thinking about assessment and worrying that one would not do well \\
\cline { 2 - 3 } $\begin{array}{l}\text { Negative } \\
\text { engagement }\end{array}$ & Uncertain control & Being not in control and uncertain over how to do well \\
\cline { 2 - 3 } & Self-sabotage & Engaging in activities that do not help one in doing well at work \\
\cline { 2 - 3 }
\end{tabular}

Sources: Martin (2007, 2009, 2016a)

\section{Research model}

Jarvis et al. (2003) and MacKenzie et al. (2005) explain that there are two types of measurement models, i.e. reflective and formative models. In a reflective model, a latent construct is manifested by its indicators; whereas in a composite model, a latent construct is formed by its indicators. When conceptualized at a higherorder level, a latent construct can have its dimensions as either formative or reflective indicators. By varying reflective and formation models at the first-order and second-order levels, there can be four different types of second-order models: reflective-reflective (type I model), reflective-formative (type II model), formativereflective (type III model), and formative-formative (type IV model).

Figure 1 illustrates the research model. Modelled as a higher-order structure, positive motivation, positive engagement, negative motivation, and negative engagement are the second-order formative constructs. At the second-order construct level, positive motivation is manifested by three first-order reflective constructs of self-belief, learning focus, and valuing; positive engagement by three reflective constructs of persistence, planning, and task management; negative motivation by three reflective constructs of anxiety, failure avoidance, and uncertain control; and negative engagement by two reflective constructs of self-sabotage and disengagement. Each first-order reflective construct is manifested by four indicators. All indicators are measured using a 7-point Likert-type scale, 7 being "strongly agree" and 1 being "strongly disagree."

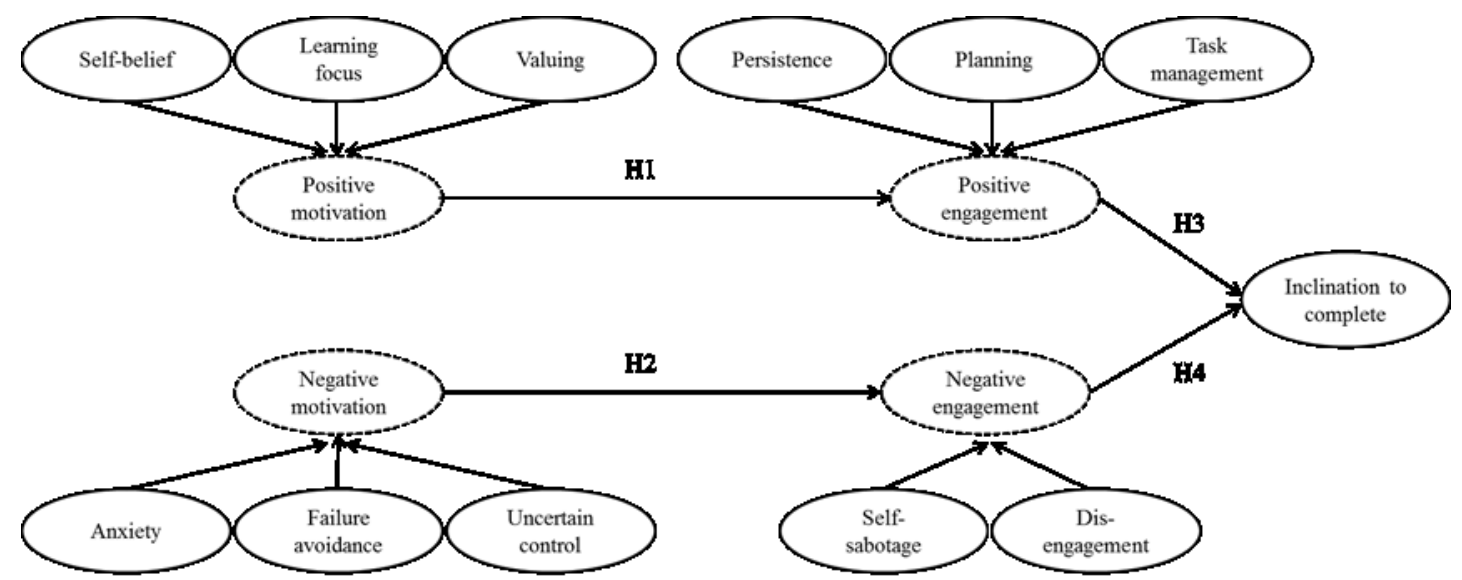

\section{Denotes second-order formative construct}

Figure 1: Research model

In educational settings, to understand the effect of student motivation and engagement levels, research studies have used different outcomes, e.g. educational aspirations, class participation, enjoyment of school (Green et al., 2007; Martin, 2007); mastery of generic skills such as problem-solving, analytical, communication (Yin, 2018); and personal and social gains, general educational growth, practical competence, current GPA 
(Hsieh, 2014). In this study, the outcome construct is learners' inclination to complete a MOOC if they were to enroll in one. It is a first-order reflective construct manifested by three indicators. The indicators are measured using an 11-point Likert-type scale, 10 being "most likely" and 0 being "least likely."

Taking the cue from Martin et al. (2017) that motivation may help encourage engagement, this study proposes to model motivation as the predictor for engagement. Hypotheses $\mathrm{H} 1$ and $\mathrm{H} 3$ predict that positive motivation leads to positive engagement behaviours in learners, which eventually promote a higher level of inclination to complete a MOOC if they were to enroll in one. Hypotheses $\mathrm{H} 2$ and $\mathrm{H} 4$ predict that negative motivation leads to negative engagement behaviours in learners, which eventually contribute to a lower level of inclination to complete a MOOC if they were to enroll in one.

\section{Research methods}

\subsection{Instrument development}

License was obtained from Lifelong Achievement Group (Martin, 2016a, 2016b) to use the MES instrument in this study. In addition, this study also designed a questionnaire to be administered along with the MES instrument. The questionnaire consisted of four sections. Section A asked two questions on whether the participants had enrolled in any MOOC in the past, and if "no", whether they plan to enrol in any MOOC in the future. Section B asked the participants who had enrolled in any MOOC in the past five questions about their MOOC experience. Section $C$ asked the participants three questions about their inclination to complete if they were to enroll in a MOOC. Section D asked three demographic questions.

\subsection{Data collection}

Both the MES instrument and questionnaire were printed and administered in five tutorial classes of two undergraduate business modules in early May 2018. Fredricks and McColskey (2012) explain that self-report approach is a common method for student engagement studies as it captures the emotional and cognitive perception of the respondents. A brief introduction to the survey was first given and the respondents were assured of completely voluntary and anonymous participation. A total of 103 valid responses were received.

\subsection{Respondents' profile}

Of the 103 respondents, 50 (48.5\%) were male students and 53 (51.5\%) were female. All of them were doing business-related courses, e.g. business administration, accounting and finance, and so on. 15 (14.6\%) of them were in their $1^{\text {st }}$ or $2^{\text {nd }}$ semester, $54(52.4 \%)$ in the $3^{\text {rd }}$ or $4^{\text {th }}$ semester, and $34(33 \%)$ in the $5^{\text {th }}$ semester or later. The average age of the participants was 21.3 years old.

Only six (5.8\%) of the 103 respondents had enrolled in a MOOC in the past. Table 2 provides a general profile of these respondents. Common reasons to enrol in a MOOC were: continuous learning (66.7\%), flexible learning $(50 \%)$, course contents (50\%), wide range of courses (33.3\%), course certification (16.7\%), and career development (16.7\%).

Table 2: Profile of the respondents who had enrolled in a MOOC in the past

\begin{tabular}{|l|l|c|c|}
\hline Items & Responses & $\mathrm{N}$ & $\%$ \\
\hline \multirow{4}{*}{$\begin{array}{l}\text { Number of MOOCs completed in } \\
\text { the past }\end{array}$} & One MOOC & 4 & $66.7 \%$ \\
\cline { 2 - 4 } & Two MOOCs & 1 & 16.7 \\
\cline { 2 - 4 } & Eight MOOCs & 1 & $16.7 \%$ \\
\hline \multirow{4}{*}{$\begin{array}{l}\text { MOOC platforms that had been } \\
\text { used }\end{array}$} & Coursera & 4 & $66.7 \%$ \\
\cline { 2 - 4 } & Udemy & 1 & $16.7 \%$ \\
\cline { 2 - 4 } & $\begin{array}{l}\text { Others (e.g. OpenLearning, Course } \\
\text { Number of MOOCs currently }\end{array}$ & 3 & $50 \%$ \\
\hline \multirow{3}{*}{$\begin{array}{l}\text { Number of study hours normally } \\
\text { spent on a MOOC each week }\end{array}$} & One MOOC & 3 & $50 \%$ \\
\cline { 2 - 4 } & Three MOOCs & 1 & $16.7 \%$ \\
\cline { 2 - 4 } & Four MOOCs & 1 & $16.7 \%$ \\
\cline { 2 - 4 } & Nil & 1 & $16.7 \%$ \\
\cline { 2 - 4 } & Bess than one hour & 1 & $66.7 \%$ \\
\cline { 2 - 4 } & Between one to three hours & 1 & $16.7 \%$ \\
\hline
\end{tabular}


Of the majority of the respondents (94.2\%) who did not enrol in a MOOC in the past, $59(60.8 \%)$ of them planned to do so in the next one to six months, $10(10.3 \%)$ of them in the next seven to 12 months, $10(10.3 \%)$ of them after 12 months, and 18 (18.6\%) of them did not intend to take any MOOC.

\section{Data analysis and results}

\subsection{Confirmatory factor analysis}

This study followed a two-step partial least squares (PLS) approach to do a confirmatory factor analysis (CFA) (Anderson and Gerbing, 1988). First, the measurement model was assessed for internal consistency reliability, convergent validity, and discriminant validity (Dunn et al., 1994). Next, the structural model was assessed for significance of the path coefficients and coefficient of determination $\left(R^{2}\right)$ (Anderson and Gerbing, 1988). To perform the PLS analysis, this study used SmartPLS 3 Professional (Ringle et al., 2015).

As the relationships between a construct and its indicators are prescribed before the CFA (Gefen and Straub, 2005), an inter-item correlation analysis was first performed on all of the first-order reflective constructs to check for scale parsimony (Gable et al., 2008). An indicator was removed if its inter-item correlation with any other indicator in the same scale is below 0.30 (Hackman et al., 2006; Sundin et al., 2008). The results of the analysis showed that TAS_2 of task management, DIS_1 of disengagement, and ANX_3 of anxiety had a poor inter-item correlation with any other indicator in their respective scales. Thus, they were removed from further analyses. All scales showed good Cronbach's Alpha reliability of above 0.7 , except that of anxiety (0.666).

\subsubsection{First-order reflective measurement model}

First-order reflective constructs were assessed for internal consistency reliability, convergent validity, and discriminant validity.

Internal consistency reliability - The loadings of indicators were examined for indicator reliability. Those that did not load above 0.708 on the intended construct were deleted to establish unidimensionality (Hair et al., 2014). The following indicators did not meet the threshold value and were subsequently removed from further analyses: VAL_2 (0.561) of valuing; PLA_1 (0.681) and PLA_4 (0.580) of planning; SAB_1 (0.630) of selfsabotage, and ANX_2 (0.310) of anxiety. After they were removed, loadings of all indicators on their intended constructs were above 0.708, except that of BEL_1 (0.676) and BEL_2 (0.694) of self-belief. Although these two indicators did not meet the threshold value, deleting them would result in lower composite reliability for selfbelief. Thus, it was decided to still keep them in the analysis.

In addition, for satisfactory internal consistency reliability, composite reliability of a reflective construct should exceed 0.708 (Chin, 1998, Fornell and Larcker, 1981). As evident in Table 3, composite reliability of all constructs was above $\mathbf{0 . 7 0 8}$. Thus, internal consistency reliability of individual constructs was satisfactory.

Table 3: $C R, A V E$, and construct correlations

\begin{tabular}{|c|c|c|c|c|c|c|c|c|c|c|c|c|c|c|}
\hline & CR & AVE & ANX & DIS & FAI & LEA & INC & PER & PLA & BEL & SAB & TAS & UNC & VAL \\
\hline ANX & 0.799 & 0.665 & 0.815 & & & & & & & & & & & \\
\hline DIS & 0.868 & 0.686 & 0.125 & 0.828 & & & & & & & & & & \\
\hline FAI & 0.901 & 0.695 & 0.245 & 0.223 & 0.834 & & & & & & & & & \\
\hline LEA & 0.870 & 0.626 & 0.271 & -0.126 & 0.063 & 0.791 & & & & & & & & \\
\hline INC & 0.919 & 0.791 & 0.154 & -0.196 & -0.042 & 0.253 & 0.890 & & & & & & & \\
\hline PER & 0.858 & 0.602 & 0.041 & -0.214 & 0.043 & 0.476 & 0.358 & 0.776 & & & & & & \\
\hline PLA & 0.928 & 0.865 & 0.033 & -0.130 & 0.109 & 0.291 & 0.296 & 0.623 & 0.930 & & & & & \\
\hline BEL & 0.814 & 0.524 & 0.076 & -0.301 & 0.222 & 0.410 & 0.193 & 0.530 & 0.342 & 0.724 & & & & \\
\hline SAB & 0.895 & 0.740 & 0.075 & 0.458 & 0.347 & -0.068 & -0.090 & -0.284 & -0.121 & -0.176 & 0.861 & & & \\
\hline TAS & 0.851 & 0.658 & 0.241 & -0.039 & 0.159 & 0.434 & 0.177 & 0.480 & 0.428 & 0.444 & -0.188 & 0.811 & & \\
\hline UNC & 0.869 & 0.625 & 0.214 & 0.575 & 0.292 & -0.123 & -0.069 & -0.224 & -0.129 & -0.287 & 0.447 & -0.059 & 0.790 & \\
\hline VAL & 0.861 & 0.674 & 0.008 & -0.105 & 0.079 & 0.465 & 0.297 & 0.659 & 0.618 & 0.419 & -0.140 & 0.479 & -0.151 & 0.821 \\
\hline
\end{tabular}


Convergent validity - For satisfactory convergent validity, the average variance extracted (AVE) of a construct should be above 0.5 (Chin, 1998; Fornell and Larcker, 1981). When the AVE is above 0.5, the variance of individual constructs is larger than that contributed by the measurement error (Segars, 1997). As shown in Table 3, the AVEs of all constructs were above 0.5. Thus, it was evident that all constructs had satisfactory convergent validity.

Discriminant Validity - For satisfactory discriminant validity, the indicators should load higher on the intended construct, but lower on the other unintended constructs (Chin, 1998); and the square root of the AVE of a latent construct should be larger than the correlation between that construct and any other constructs in the model (Fornell and Larcker, 1981; Gefen and Straub, 2005). Table 3 shows that the square root of the AVE of individual constructs was higher than the correlation between it and any other constructs. Table 4 shows that the indicators loaded higher on their intended constructs and significantly lower on any other constructs.

Table 4: Factor loadings and cross loadings

\begin{tabular}{|c|c|c|c|c|c|c|c|c|c|c|c|c|c|}
\hline & INC & BEF & PER & LEA & VAL & TAS & PLA & DIS & SAB & UNC & FAI & ANX & $\begin{array}{c}\mathrm{P}- \\
\text { values }\end{array}$ \\
\hline INC_3 & 0.836 & 0.141 & 0.286 & 0.245 & 0.263 & 0.131 & 0.242 & -0.140 & 0.009 & 0.033 & -0.012 & 0.191 & $<0.001$ \\
\hline INC_1 & 0.915 & 0.225 & 0.304 & 0.208 & 0.282 & 0.210 & 0.270 & -0.149 & -0.118 & -0.076 & -0.021 & 0.142 & $<0.001$ \\
\hline INC_2 & 0.916 & 0.154 & 0.358 & 0.224 & 0.252 & 0.135 & 0.277 & -0.225 & -0.123 & -0.126 & -0.072 & 0.090 & $<0.001$ \\
\hline BEF_1 & 0.242 & 0.675 & 0.396 & 0.198 & 0.224 & 0.192 & 0.267 & -0.336 & -0.236 & -0.189 & 0.146 & 0.055 & $<0.001$ \\
\hline BEF_2 & 0.090 & 0.693 & 0.299 & 0.331 & 0.188 & 0.219 & 0.304 & -0.116 & -0.076 & -0.123 & 0.160 & 0.151 & $<0.001$ \\
\hline BEF_3 & 0.167 & 0.737 & 0.454 & 0.329 & 0.439 & 0.458 & 0.256 & -0.176 & -0.047 & -0.248 & 0.191 & 0.047 & $<0.001$ \\
\hline BEF_4 & 0.052 & 0.786 & 0.357 & 0.319 & 0.306 & 0.359 & 0.169 & -0.252 & -0.175 & -0.251 & 0.136 & -0.019 & $<0.001$ \\
\hline PER_1 & 0.301 & 0.448 & 0.783 & 0.423 & 0.539 & 0.404 & 0.510 & -0.216 & -0.172 & -0.140 & 0.086 & 0.088 & $<0.001$ \\
\hline PER_2 & 0.294 & 0.369 & 0.802 & 0.340 & 0.543 & 0.313 & 0.540 & -0.154 & -0.303 & -0.245 & -0.040 & 0.028 & $<0.001$ \\
\hline PER_3 & 0.311 & 0.325 & 0.768 & 0.431 & 0.489 & 0.331 & 0.465 & -0.125 & -0.266 & -0.109 & 0.045 & 0.069 & $<0.001$ \\
\hline PER_4 & 0.198 & 0.506 & 0.748 & 0.276 & 0.468 & 0.444 & 0.410 & -0.167 & -0.139 & -0.203 & 0.039 & -0.071 & $<0.001$ \\
\hline LEA_1 & 0.191 & 0.268 & 0.300 & 0.766 & 0.229 & 0.358 & 0.194 & -0.029 & -0.057 & -0.069 & 0.005 & 0.283 & $<0.001$ \\
\hline LEA_2 & 0.289 & 0.259 & 0.319 & 0.790 & 0.263 & 0.342 & 0.183 & -0.137 & -0.170 & -0.114 & -0.008 & 0.311 & $<0.001$ \\
\hline LEA_3 & 0.116 & 0.377 & 0.249 & 0.764 & 0.239 & 0.294 & 0.119 & -0.164 & 0.019 & -0.114 & 0.059 & 0.229 & $<0.001$ \\
\hline LEA_4 & 0.196 & 0.385 & 0.546 & 0.843 & 0.611 & 0.369 & 0.352 & -0.091 & -0.012 & -0.098 & 0.117 & 0.101 & $<0.001$ \\
\hline VAL_1 & 0.166 & 0.286 & 0.506 & 0.446 & 0.826 & 0.395 & 0.512 & 0.068 & -0.085 & -0.070 & 0.083 & 0.052 & $<0.001$ \\
\hline VAL_3 & 0.267 & 0.289 & 0.503 & 0.244 & 0.784 & 0.201 & 0.492 & -0.136 & 0.036 & -0.133 & 0.000 & -0.028 & $<0.001$ \\
\hline VAL_4 & 0.295 & 0.438 & 0.603 & 0.434 & 0.851 & 0.539 & 0.519 & -0.182 & -0.255 & -0.166 & 0.098 & -0.007 & $<0.001$ \\
\hline TAS_1 & 0.054 & 0.277 & 0.380 & 0.479 & 0.436 & 0.786 & 0.378 & -0.044 & -0.122 & -0.061 & 0.019 & 0.157 & $<0.001$ \\
\hline TAS_3 & 0.216 & 0.456 & 0.449 & 0.374 & 0.423 & 0.889 & 0.380 & -0.094 & -0.199 & -0.084 & 0.216 & 0.208 & $<0.001$ \\
\hline TAS_4 & 0.155 & 0.335 & 0.322 & 0.158 & 0.285 & 0.752 & 0.266 & 0.080 & -0.128 & 0.025 & 0.146 & 0.234 & $<0.001$ \\
\hline PLA_2 & 0.290 & 0.298 & 0.540 & 0.267 & 0.601 & 0.364 & 0.936 & -0.080 & -0.067 & -0.096 & 0.099 & 0.060 & $<0.001$ \\
\hline PLA_3 & 0.260 & 0.340 & 0.622 & 0.275 & 0.548 & 0.435 & 0.924 & -0.166 & -0.161 & -0.147 & 0.105 & -0.001 & $<0.001$ \\
\hline DIS_2 & -0.212 & -0.305 & -0.233 & -0.138 & -0.184 & -0.150 & -0.197 & 0.813 & 0.350 & 0.497 & 0.205 & 0.149 & $<0.001$ \\
\hline DIS_3 & -0.163 & -0.229 & -0.161 & -0.149 & -0.051 & 0.022 & -0.056 & 0.812 & 0.395 & 0.441 & 0.047 & 0.079 & $<0.001$ \\
\hline DIS_4 & -0.110 & -0.209 & -0.133 & -0.028 & -0.017 & 0.043 & -0.060 & 0.859 & 0.397 & 0.486 & 0.287 & 0.077 & $<0.001$ \\
\hline SAB_2 & -0.110 & -0.195 & -0.304 & -0.088 & -0.172 & -0.203 & -0.205 & 0.357 & 0.884 & 0.464 & 0.323 & 0.049 & $<0.001$ \\
\hline SAB_3 & 0.005 & -0.095 & -0.114 & -0.048 & 0.010 & -0.149 & 0.060 & 0.361 & 0.861 & 0.285 & 0.330 & 0.055 & $<0.001$ \\
\hline SAB_4 & -0.112 & -0.147 & -0.287 & -0.029 & -0.174 & -0.123 & -0.124 & 0.475 & 0.837 & 0.375 & 0.241 & 0.094 & $<0.001$ \\
\hline UNC_1 & 0.048 & -0.188 & -0.103 & -0.006 & -0.046 & -0.140 & -0.043 & 0.317 & 0.302 & 0.741 & 0.043 & 0.121 & $<0.001$ \\
\hline UNC_2 & -0.003 & -0.246 & -0.246 & -0.068 & -0.228 & -0.077 & -0.115 & 0.377 & 0.431 & 0.714 & 0.398 & 0.289 & $<0.001$ \\
\hline UNC_3 & -0.070 & -0.215 & -0.159 & -0.118 & -0.073 & 0.049 & -0.050 & 0.544 & 0.329 & 0.845 & 0.122 & 0.165 & $<0.001$ \\
\hline UNC_4 & -0.155 & -0.253 & -0.187 & -0.165 & -0.122 & -0.051 & -0.186 & 0.535 & 0.350 & 0.851 & 0.322 & 0.104 & $<0.001$ \\
\hline FAI_1 & -0.035 & 0.188 & 0.068 & 0.085 & 0.116 & 0.172 & 0.125 & 0.212 & 0.303 & 0.306 & 0.869 & 0.264 & $<0.001$ \\
\hline FAI_2 & 0.021 & 0.209 & 0.068 & 0.074 & 0.091 & 0.125 & 0.159 & 0.138 & 0.277 & 0.240 & 0.842 & 0.148 & $<0.001$ \\
\hline FAI_3 & -0.036 & 0.236 & 0.048 & 0.112 & 0.113 & 0.309 & 0.003 & 0.127 & 0.204 & 0.192 & 0.763 & 0.233 & $<0.001$ \\
\hline FAI_4 & -0.075 & 0.140 & -0.024 & -0.024 & -0.023 & 0.005 & 0.064 & 0.236 & 0.343 & 0.224 & 0.856 & 0.182 & $<0.001$ \\
\hline ANX_1 & 0.058 & -0.090 & -0.086 & 0.099 & -0.062 & 0.131 & -0.041 & 0.087 & 0.077 & 0.273 & 0.120 & 0.798 & $<0.05$ \\
\hline ANX_4 & 0.189 & 0.202 & 0.142 & 0.334 & 0.070 & 0.257 & 0.090 & 0.116 & 0.047 & 0.084 & 0.274 & 0.832 & $<0.01$ \\
\hline
\end{tabular}

Note:

${ }^{1}$ BEL: Self-belief; PER: Persistence; LEA: Learning focus; VAL: Valuing; TAS: Task management; PLA: Planning; DIS: Disengagement; SAB: Self-sabotage; UNC: Uncertain control; FAI: Failure avoidance; ANX: Anxiety; INC: Inclination to complete

${ }^{2}$ To comply with the terms and conditions as prescribed in the MES license, the scale items are not reproduced in this paper. 


\subsubsection{Second-order formative measurement model}

To assess the second-order formative constructs, this study followed the suggestion of Hair et al. (2014). First, latent variable scores of the first-order reflective constructs were obtained. Then, these latent variable scores were used as the indicators for their respective second-order formative constructs. These formative constructs were then assessed for indicator weight and significance, and multicollinearity (Hair et al., 2014).

The outer weight and significance of an indicator is examined to determine its relative importance to a formative construct (Hair et al., 2014). An initial analysis showed that the outer weights of four indicators were statistically not significant, i.e. learning focus $(p=0.133)$, planning $(p=0.072)$, failure avoidance $(p=0.155)$, and anxiety $(p=0.679)$. Hair et al. (2014) suggest that if the outer weight of an indicator is not significant but its outer loading is above 0.5 , the indicator can be retained in the model. Learning focus and planning met this criterion. Thus, they were retained. On the other hand, when the outer weight of an indicator is not significant and its outer loading is below 0.5 but significant, the indicator may be retained. Failure avoidance met this criterion. Thus, it was retained as well. However, when the outer loading is below 0.5 and not significant, the indicator can be deleted. Anxiety met this criterion. Thus, it was deleted.

Table 5 provides a summary of the final weights of the indicators for positive motivation, positive engagement, negative motivation, and negative engagement. In terms of relative importance, valuing (0.694) contributed more than self-belief $(0.345)$ to positive motivation; persistence (0.658) contributed more than task management $(0.258)$ to positive engagement; uncertain control (0.909) contributed most to negative motivation; and disengagement (0.737) contributed more than self-sabotage (0.417) to negative engagement. For indicators that had nonsignificant outer weights, their outer loadings determined their absolute contribution to the formative constructs (Hair et al., 2014). In this case, the absolute contribution of learning focus to positive motivation was 0.644 ; that of planning to positive engagement was 0.780 ; and that of failure avoidance to negative motivation was 0.494 .

Table 5: Outer weights of second-order formative constructs

\begin{tabular}{|c|c|c|c|c|c|c|c|}
\hline \multirow{2}{*}{$\begin{array}{l}\text { First-order reflective } \\
\text { constructs }\end{array}$} & \multirow[b]{2}{*}{ VIF } & \multicolumn{4}{|c|}{ Second-order formative constructs } & \multirow[b]{2}{*}{ T-statistics } & \multirow[b]{2}{*}{ P-values } \\
\hline & & $\begin{array}{c}\text { Positive } \\
\text { motivation }\end{array}$ & $\begin{array}{c}\text { Positive } \\
\text { engagement }\end{array}$ & $\begin{array}{c}\text { Negative } \\
\text { motivation }\end{array}$ & $\begin{array}{c}\text { Negative } \\
\text { engagement }\end{array}$ & & \\
\hline Valuing & 1.387 & 0.694 & & & & 5.981 & 0.000 \\
\hline Self-belief & 1.306 & 0.345 & & & & 2.846 & 0.004 \\
\hline Learning focus $^{1}$ & 1.374 & 0.180 & & & & 1.503 & 0.136 \\
\hline Persistence & 1.797 & & 0.658 & & & 5.801 & 0.000 \\
\hline Planning $^{2}$ & 1.694 & & 0.260 & & & 1.797 & 0.077 \\
\hline Task management & 1.347 & & 0.258 & & & 2.599 & 0.009 \\
\hline Uncertain control & 1.119 & & & 0.909 & & 10.375 & 0.000 \\
\hline Failure avoidance $^{3}$ & 1.137 & & & 0.229 & & 1.423 & 0.149 \\
\hline Disengagement & 1.266 & & & & 0.737 & 5.115 & 0.000 \\
\hline Self-sabotage & 1.266 & & & & 0.417 & 2.509 & 0.011 \\
\hline \multicolumn{8}{|c|}{$\begin{array}{l}\text { Notes: } \\
{ }^{1} \text { Learning focus was retained - outer loading was } 0.644 \text { and significant }(p<0.005) \\
2 \text { Planning was retained - outer loading was } 0.780 \text { and significant }(p<0.005) \\
{ }^{3} \text { Failure avoidance was retained - although outer loading was below } 0.5(0.494) \text { but significant }(p<0.005)\end{array}$} \\
\hline
\end{tabular}

As each of the indicators for a formative construct constitutes a specific aspect of its conceptual domain, the indicators should not correlate highly with each other (Diamantopoulos and Winklhofer, 2001; Jarvis et al., 2003). To assess if there are multicollinearity issues, the variance inflation factor (VIF) value of each indicator should be below 5.0 (Hair et al., 2014). Table 5 shows that the VIF values of all indicators were below 5.0. Thus, multicollinearity issues did not exist.

\subsubsection{Structural model}

The structural model was assessed next for significance of path coefficients between two constructs and coefficient of determination $\left(R^{2}\right)$ of endogenous constructs (Urbach and Ahlemann, 2010). 
A bootstrapping procedure of 5,000 sub-samples calculated the t-statistics of path coefficients between the exogenous and endogenous constructs (Gefen et al., 2000). Figure 2 depicts the final structural model (without showing anxiety as it was deleted).

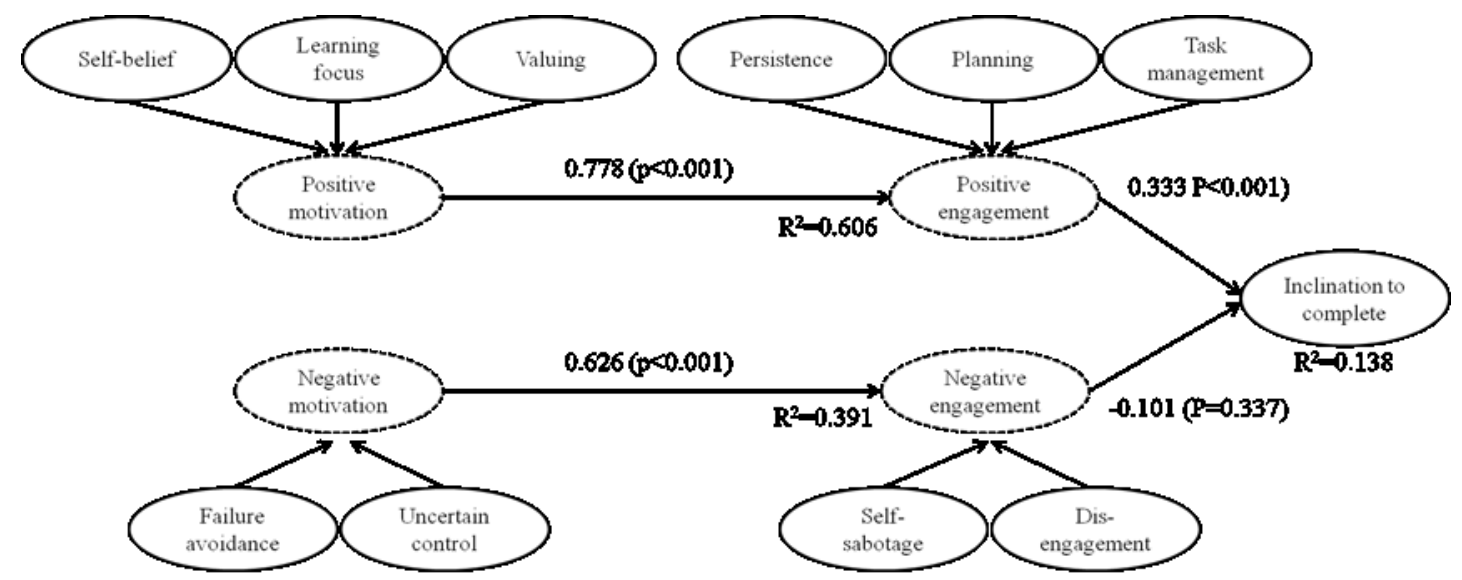

\section{(.) Denotes second-order formative construct}

Figure 2: Final structural model

The relationships between positive motivation and positive engagement, between negative motivation and negative engagement, and between positive engagement and inclination to complete were statistically significant and positive. Although the relationship between negative engagement and inclination to complete was negative as hypothesised, it was not statistically significant $(\beta=-0.101, p=0.337)$. With the negative engagement construct removed from the model, another bootstrapping procedure showed that the relationship between negative motivation and inclination to complete was also not significant $(\beta=-0.024$, $\mathrm{p}=0.860$ ).

Positive motivation explained about $60 \%$ of the variance in positive engagement $\left(R^{2}=0.606\right)$, while negative motivation explained about $39 \%$ of the variance in negative engagement $\left(R^{2}=0.391\right)$. As the relationship between negative engagement and inclination to complete was not significant, without considering this relationship, positive engagement explained about $12.8 \%$ in inclination to complete $\left(R^{2}=0.128\right)$.

\section{Discussion and conclusion}

Only about $6 \%$ of the respondents had enrolled in a MOOC in the past. This finding is quite similar to that of a 2015 online survey by Statista.com (2015), which found that only $9 \%$ of some 50,000 undergraduate students worldwide took a MOOC in the past year. In the same survey, it was also reported that $74 \%$ did not know what a MOOC was, and $17 \%$ knew what a MOOC was but had not actually taken one. In this study, it seems that the respondents had shown a general interest in MOOCs, with about $81.4 \%$ of them expressing an intention to enroll in a MOOC in the next one to 12 months.

Although a few indicators were removed from the first-order reflective measurement model, this study concurred with other studies (e.g. Martin et al., 2015; Martin et al., 2017; Martin et al., 2018) that the scale reliability and validity of the MES constructs were clearly evident. In addition, when used as an indicator for the second-order formative construct of negative motivation, although anxiety was deleted because of statistically nonsignificant outer weight and outer loading, the overall structure of the Wheel remained intact. In this case, the respondents did not seem to consider anxiety a key element to negative motivation as much as failure avoidance and uncertain control. It may be that the respondents were sufficiently self-confident to not worry too much about not being able to do well in assessment tasks. Nevertheless, MOOC providers should still provide the necessary support to help learners reduce uncertainty and anxiety (Chen and Jang, 2010).

The findings provide support for hypotheses $\mathrm{H} 1$ and $\mathrm{H} 3$ that positive motivation leads to positive engagement behaviours in learners, which eventually promote a higher level of inclination to complete MOOCs. This coincides with Lee et al. (2016) and Martin et al. (2017) that motivation is the driving force of engagement. 
Law et al. (2010), in a study of undergraduate students taking computer programming courses underpinned by an e-learning system, reported similar findings that "individual attitude and expectation", "clear direction", and "reward and recognition" are the top motivation factors for e-learners. Thus, for MOOC providers to improve completion rates of their courses, they should help learners to develop higher levels of self-belief, learning focus, and valuing.

Ben-Eliyahu et al. (2018), in their study of students participating in several learning activities to examine whether motivation in an initial learning stage affected engagement and the subsequent effect of engagement on motivation in a later learning stage, reported that there was a positive reciprocal relationship between motivation and engagement. Taking the cue from their findings, MOOC providers should recognise the importance of facilitating a learning environment that actively engage learners, e.g. providing proper learning support, for long-term motivation (Oga-Baldwin et al., 2017). Lee et al. (2016) stress that engaging learning activities would help enhance learner motivation, e.g. promoting learning autonomy and developing learning interest, which leads to better engagement and learning outcomes.

MOOC providers could also provide learners with tools or technologies to support better planning, task management, and persistence in their pursue of MOOCs. Lin et al. (2017), in a study of high-school students learning language online, reported that learning strategies such as goal-setting, self-evaluation, organizing, and seeking assistance are helpful for the students in achieving the learning outcomes. Chen and Chen (2015) recommend that a MOOC study group for learners to share learning strategies, as well as to build a community spirit, is useful for fostering learners' motivation, engagement, and deep learning.

The findings also provide support for hypothesis $\mathrm{H} 2$ that negative motivation leads to negative engagement behaviours in learners. Although the relationship between negative engagement behaviours and inclination to complete MOOCs was not statistically significant, the findings provide partial support for hypothesis $\mathrm{H} 4$ that negative engagement behaviours may contribute to a lower level of inclination to complete MOOCs. In this case, there may be negative engagement behaviours; however, these negative engagement behaviours may not have as significant an effect as that of positive engagement behaviours on inclination to complete MOOCs. Thus, MOOC providers and learners should employ strategies to reduce levels of failure avoidance and uncertain control, and to refrain from self-sabotage and disengagement practices.

The findings from this study can help MOOC providers to better understand how to develop effective motivation and engagement strategies to encourage learners towards better completion rates of MOOCs. The findings can also serve as a springboard for MOOC learners to reflect on the importance of staying motivated and engaged, and to learn helpful motivation and engagement practices for high levels of course achievement and completion.

\subsection{Research limitation}

This study has two major research limitations. First, most respondents in this study did not enroll in any MOOC in the past. Although it was still valid for the study to ask them for their opinions about their inclination to complete a MOOC if they were to actually enroll in one, their opinions might be different from those who have actually enrolled in one. Second, MOOC learners are heterogeneous in terms of their reasons to enroll in MOOCs (Chen and Jang, 2010), motivation levels (Alario-Hoyos et al., 2017), and background characteristics, e.g. gender, socio-economics status, academic disciplines (Bolliger et al., 2010; Hsieh, 2014); therefore, it may not be appropriate to treat the findings as from a homogeneous group.

\subsection{Future research directions}

Three future research directions may be suggested. First, the same study can be conducted to target respondents who have actually enrolled in a MOOC and examine if there are significant differences between actual users and prospective users of MOOCs. Second, considering the internationalisation of higher education (Schuerholz-Lehr, 2007), the same study can be replicated in other cultural settings for comparison purposes in terms of learning motivation and engagement of culturally diverse learners. Third, future studies can further investigate the moderating effects of learners' background characteristics on their learning motivation and engagement. 


\section{References}

Alario-Hoyos, C., Estévez-Ayres, I., Pérez-Sanagustín, M., Delgado Kloos, C. and Fernández-Panadero, C., 2017. Understanding learners' motivation and learning strategies in MOOCs. International Review of Research in Open and Distributed Learning, 18(3), pp.119-137.

Alraimi, K.M., Zo, H.J. and Ciganek, A.P., 2015. Understanding the MOOCs continuance: The role of openness and reputation. Computers \& Education, 80, pp.28-38.

Anderson, J.C. and Gerbing, D.W., 1988. Structural equation modeling in practice: A review and recommended two-step approach. Psychological Bulletin, 103, pp.411-423.

Ben-Eliyahu, A., Moore, D., Dorph, R. and Schunn, C.D., 2018. Investigating the multidimensionality of engagement: affective, behavioral, and cognitive engagement in science across multiple days, activities, and contexts. Contemporary Educational Psychology, 53, pp.87-105.

Bolliger, D.U., Supanakorn, S. and Boggs, C., 2010. Impact of podcasting on student motivation in the online learning environment. Computers \& Education, 55(2), pp.714-722.

Cazan, A.M., 2015. Learning motivation engagement and burnout among university students. Procedia-Social and Behavioral Sciences, 187, pp.413-417.

Chen, K. C. and Jang, S.J., 2010. Motivation in online learning: Testing a model of self-determination theory. Computers in Human Behavior, 26, pp.741-752.

Chen, Y.H. and Chen, P.J., 2015. MOOC study group: Facilitation strategies, influential factors, and student perceived gains. Computers \& Education, 86, pp.55-70.

Chen, Y.L.E. and Kraklow, D., 2015. Taiwanese college students' motivation and engagement for English learning in the context of internationalization at home: A comparison of students in EMI and non-EMI programs. Journal of Studies in International Education, 19(1), pp.46-64.

Chin, W.W., 1998. Commentary: Issues and opinion on structural equation modeling. MIS Quarterly, 22, pp.vii-xvi.

Clayton, K., Blumberg, F. and Auld, D.P., 2010. The relationship between motivation, learning strategies and choice of environment whether traditional or including an online component. British Journal of Educational Technology, 41(3), pp.349-364.

Diamantopoulos, A. and Winklhofer, H.M., 2001. Index construction with formative indicators: An alternative to scale development. Journal of Marketing Research, 38, pp.269-277.

Dunn, S.C., Seaker, R.F. and Waller, M.A., 1994. Latent variables in business logistics research: Scale development and validation. Journal of Business Logistics, 15(2), pp.145-172.

Eseryel, D., Law, V., Ifenthaler, D., Ge, X. and Miller, R., 2014. An investigation of the interrelationships between motivation, engagement, and complex problem solving in game-based learning. Educational Technology \& Society, 17(1), pp.42-53.

Fornell, C. and Larcker, D.F., 1981. Structural equation models with unobservable variables and measurement error: Algebra and statistics. Journal of Marketing Research, 18, pp.382-388.

Fredricks, J.A. and McColskey, W., 2012. The measurement of student engagement: A comparative analysis of various methods and student self-report instruments. In: S.L. Christenson, A.L. Reschly and C. Wylie, eds. Handbook of research on student engagement. New York: Springer. pp.763-782.

Gable, G.G., Sedera, D. and Chan, T., 2008. Re-conceptualising information system success: The IS-impact measurement model. Journal of the Association for Information Systems, 9(7), pp.377-408.

Gefen, D. and Straub, D., 2005. A practical guide to factorial validity using PLS-Graph: tutorial and annotated example. Communications of the Association for Information Systems, 16, pp.91-109.

Gefen, D., Straub, D. W. and Boudreau, M., 2000. Structural equation modeling and regression: Guidelines for research practice. Communications of the Association for Information Systems, 4, pp.1-77.

Green, J., Liem, G.D., Martin, A.J., Colmar, S., Marsh, H.W. and McInerney, D., 2012. Academic motivation, self-concept, engagement, and performance in high school: Key processes from a longitudinal perspective. Journal of Adolescence, 35, pp.1111-1122.

Green, J., Martin, A.J. and Marsh, H.W., 2007. Motivation and engagement in English, mathematics and science high school subjects: Towards an understanding of multidimensional domain specificity. Learning and Individual Differences, 17(3), pp.269-279.

Hackman, D., Gundergan, S., Wang, P. and Daniel, K., 2006. A service perspective on modelling intentions of on-line purchasing. Journal of Services Marketing, 20(6/7), pp.459-470.

Hair, J.F., Hult, G.T.M., Ringle, C.M. and Sarstedt, M., 2014. A Primer on Partial Least Squares Structural Equation Modeling. Thousand Oaks: Sage.

Hew, K.F. and Cheung, W.S., 2014. Students and instructors use of massive open online courses (MOOCs): motivations and challenges. Educational Research Review, 12, pp.45-58.

Hone, K.S. and El Said, G.R., 2016. Exploring the factors affecting MOOC retention: A survey Study. Computers \& Education, 98, pp.157-168.

Hornstra, L., Stroet, K., Eijden, E.V., Goudsblom, J. and Roskamp, C., 2018. Teacher expectation effects on need-supportive teaching, student motivation, and engagement: A self-determination perspective, Educational Research and Evaluation, 24(3-5), pp.324-345. 
Hsieh, T.L., 2014. Motivation matters? The relationship among different types of learning motivation, engagement behaviors and learning outcomes of undergraduate students in Taiwan. Higher Education, 68(3), pp.417-433.

Jarvis, C.B., MacKenzie, S.B. and Podsakoff, P.M., 2003. A critical review of construct indicators and measurement model misspecification in marketing and consumer research. Journal of Consumer Research, 30, pp.199-218.

Jung, Y. and Lee, J., 2018. Learning engagement and persistence in massive open online courses (MOOCs). Computers \& Education, 122, pp.9-22.

Law, K.M.Y., Lee, V.C.S. and Yu, Y.T., 2010. Learning motivation in e-learning facilitated computer programming courses. Computers \& Education, 55(1), pp.218-228.

Lee, C. S., Hayes, K.N., Seitz, J., DiStefano, R. and O'Connor, D., 2016. Understanding motivational structures that differentially predict engagement and achievement in middle school science. International Journal of Science Education, 38(2), pp.192-215.

Liem, G.A. and Martin, A.J., 2012. The motivation and engagement scale: Theoretical framework, psychometric properties, and applied yields. Australian Psychologist, 47, pp.3-13.

Lin, C.H., Zhang, Y. and Zheng, B., 2017. The roles of learning strategies and motivation in online language learning: a structural equation modeling analysis. Computers \& Education, 113, pp.75-85.

MacKenzie, S.B., Podsakoff, P.M. and Jarvis, C.B., 2005. The problem of measurement model misspecification in behavioral and organisational research and some recommended solutions. Journal of Applied Psychology, 90(4), pp.710-730.

Major, C.H. and Blackmon, S.J., 2016. Massive open online courses: variations on a new instructional form. In: C.H. Major and S.J. Blackmon, eds. MOOCs and higher education: Implications for institutional research: new directions for institutional research, San Francisco: Jossey-Bass. pp.11-25.

Martin A.J., Ginns, P. and Papworth B., 2017. Motivation and engagement: Same or different? Does it matter? Learning and Individual Differences, 55, pp.150-162.

Martin, A.J. and Elliot, A.J., 2016. The role of personal best (PB) and dichotomous achievement goals in students' academic motivation and engagement: A longitudinal investigation. Educational Psychology, 36(7), pp.1285-1302.

Martin, A.J., 2007. Examining a multidimensional model of student motivation and engagement using a construct validation approach. British Journal of Educational Psychology, 77, pp.413-440.

Martin, A.J., 2009. Motivation and engagement across the academic lifespan: A developmental construct validity study of elementary school, high school, and university/college students. Educational and Psychological Measurement, 69, pp.794-824.

Martin, A.J., 2016a. The motivation and engagement workbook (16th ed.). Sydney, Australia: Lifelong Achievement Group (www.lifelongachievement.com).

Martin, A.J., 2016b. The motivation and engagement scale (16th ed.). Sydney, Australia: Lifelong Achievement Group (www.lifelongachievement.com).

Martin, A.J., Mansour, M. and Malmberg, L.E., 2019. What factors influence students' real-time motivation and engagement? An experience sampling study of high school students using mobile technology. Educational Psychology, DOI:10.1080/01443410.2018.1545997.

Martin, A.J., Martin, T.G. and Evans, P., 2018. Motivation and engagement in Jamaica: Testing a multidimensional framework among students in an emerging regional context. Journal of Psychoeducational Assessment, 36(3), pp.233-248.

Martin, A.J., Yu, K., Papworth, B., Ginns, P. and Collie, R.J., 2015. Motivation and engagement in USA, Canada, United Kingdom, Australia, and China: Testing a multidimensional framework. Journal of Psychoeducational Assessment, 33, pp.103-114.

Maxwell, W.D., Fabel, P.H., Diaz, V., Walkow, J.C., kwiek, N.C., Kanchanaraksa, S., Wamsley, M., Chen, A. and Bookstaver, P.B., 2018. Massive open online courses in U.S. healthcare education: Practical considerations and lessons learned from implementation. Currents in Pharmacy Teaching and Learning, 10(6), pp.736-743.

Mooney, J., Seaton, M., Kaur, G., Marsh, H.W. and Yeung, A.S, 2016. Cultural perspectives on indigenous and nonindigenous Australian students' school motivation and engagement, Contemporary Educational Psychology, 47, pp.11-23.

Oga-Baldwin, W.L.Q., Nakata, Y., Parker, P. and Ryan, R.M., 2017. Motivating young language learners: A longitudinal model of self-determined motivation in elementary school foreign language classes. Contemporary Educational Psychology, 49, pp.140-150.

Phan, T., McNeil, S.G., and Robin, B.R., 2016. Students' patterns of engagement and course performance in a massive open online course. Computers \& Education, 95, pp.36-44.

Ringle, C.M., Wende, S. and Becker, J.M., 2015. SmartPLS 3. [download] Available at: <http://www.smartpls.com>

Schuerholz-Lehr, S., 2007. Teaching for global literacy in higher education: How prepared are the educators? Journal of Studies in International Education, 11(2), pp.180-204.

Segars, A.H., 1997. Assessing the unidimensionality of measurement: A paradigm and illustration within the context of information systems research. Omega, 25(1), pp.107-121.

Shah, D., 2017. Massive list of MOOC providers around the world. [online] Class Central. Available at: <https://www.classcentral.com/report/mooc-providers-list/>

Shah, D., 2018a. 6 biggest MOOC trends of 2017. [online] Class Central. Available at: $<\underline{\text { https://www.class- }}$ central.com/report/6-biggest-mooc-trends-2017/> 
Shah, D., 2019. Year of MOOC-based Degrees: A Review of MOOC Stats and Trends in 2018. [online] Class Central. Available at: <https://www.classcentral.com/report/moocs-stats-and-trends-2018/>

Shapiro, H.B., Lee, C.H., Roth, N.E.W., Li, K., Cetinkaya-Rundel, M. and Canelas, D.A., 2017. Understanding the massive open online course (MOOC) student experience: An examination of attitudes, motivations, and barriers. Computers \& Education, 110, pp.35-50.

Statista, 2015. Global student awareness of massive open online courses (MOOC) as of April 2015. [online] Statista. Available at: <https://www.statista.com/statistics/548191/mooc-student-awareness-worldwide/>

Sundin, L., Hochwälder, J. and Bildt, C., 2008. A scale for measuring specific job demands within the health care sector: Development and psychometric assessment. International Journal of Nursing Studies, 45(6), pp.914-923.

Swigart, V. and Liang, Z., 2016. Digital resources for nursing education: open courseware and massive open online courses. International Journal of Nursing Sciences, 3, pp.307-313.

Urbach, N. and Ahlemann, F., 2010. Structural equation modeling in information systems research using partial least squares. Journal of Information Technology Theory and Application, 11, pp.5-40.

Watted, A. and Barak, M., 2018. Motivating factors of MOOC completers: Comparing between university affiliated students and general participants. The Internet and Higher Education, 37, pp.11-20.

Whitney, S.D. and Bergin, D.A., 2018. Students' motivation and engagement predict reading achievement differently by ethnic group, The Journal of Genetic Psychology, 179(6), pp.357-370.

Yin, H. and Wang, W., 2016. Undergraduate students' motivation and engagement in China: An exploratory study. Assessment \& Evaluation in Higher Education, 41(4), pp.601-621.

Yin, H., 2018. What motivates Chinese undergraduates to engage in learning? Insights from a psychological approach to student engagement research. Higher Education, pp.1-21.

Zhang, J., 2016. Can MOOCs be interesting to students? An experimental investigation from regulatory focus perspective. Computers \& Education, 95, pp.340-351.

Zhou, M.M., 2016. Chinese university students' acceptance of MOOCs: A self-determination perspective. Computers \& Education, 92, pp.194-203. 